\title{
Estimation of Monthly Average Daily Solar Radiation from Meteorological Parameters: Sunshine Hours and Measured Temperature in Tepi, Ethiopia
}

\author{
Girma Dejene Nage \\ Department of Physics, College of Natural and Computational Sciences, Mizan-Tepi University, Tepi, Ethiopia
}

Email address:

girmaphysics@gmail.com

To cite this article:

Girma Dejene Nage. Estimation of Monthly Average Daily Solar Radiation from Meteorological Parameters: Sunshine Hours and Measured Temperature in Tepi, Ethiopia. International Journal of Energy and Environmental Science. Vol. 3, No. 1, 2017, pp. 19-26. doi: $10.11648 /$ j.ijees.20180301.12

Received: October 14, 2017; Accepted: November 1, 2017; Published: February 28, 2018

\begin{abstract}
In this study, several equations were considered to estimate monthly average daily solar radiation from meteorological parameters: Sunshine hours and measured Temperature in Tepi, Ethiopia. These equations include the original Angstrom-Prescott linear regression and modified models (quadratic, polynomial, logarithmic and exponential functions) and temperature based models. The performance of the models was evaluated using the methods of statistical analysis. This study shows that from sunshine hours based models Samuel and Newland models are appropriate for Tepi due to their better statistical model performance analysis. From temperature based models, Chen et al., models fitted the data adequately and can be used to estimate solar radiation from temperature measurement. However, the developed correlation models give better statistical model performance analysis and therefore, it can be recommended that these models are used reasonably well for estimating the solar radiation in Tepi and possibly in its surroundings sites with similar climatic conditions if empirical coefficients are correctly calibrated.
\end{abstract}

Keywords: Solar Radiation, Meteorological Parameters, Correlation Model, Tepi

\section{Introduction}

Solar radiation at the earth's surface is the principal and fundamental energy for many physical, chemical and biological processes. Solar radiation data at ground level are important for a wide range of applications in meteorology, engineering, agricultural sciences (particularly for soil physics, agricultural hydrology, crop modeling and estimating crop evapo-transpiration), in health sector and in research of many fields of natural sciences. A few examples showing the diversity of applications may include: architecture and building design (e. g. air conditioning and cooling systems); solar heating system design and use; solar power generation and solar powered car races; weather and climate prediction models; evaporation and irrigation; calculation of water requirements for crops; monitoring plant growth and disease control and skin cancer research $[1,8,23,30]$.

Ethiopia is a high incident solar radiation country, due to its location, in the tropical zone. Therefore, there is a huge potential of utilizing solar energy for different applications, mostly in agricultural sciences, water heating and cooking purposes. Hence, estimation of this renewable energy capacity effectively through the empirical models plays an important role in developing renewable energy technologies and the sustainability of natural resources. Located in the tropics, Ethiopia receives high solar radiation, with an average potential of $5.26 \mathrm{kWh}$ per square meter per day [2, 3].

The earth rotates at an axial tilt in an elliptical orbit around the sun producing the annual variation of intensity outside the earth's atmosphere. Beneath the atmosphere solar radiation varies temporally and geographically in its: Intensity, the relative magnitudes of its direct and diffuse components, the skyward anisotropy of the diffuse component and in its spectral compositions [4, 5].

Long-term average values of the instantaneous (or hourly, daily, monthly) global and diffuse irradiations on a horizontal surface are needed in many applications of solar energy designs. The measured values of these parameters are available at a few places. At others no measurements exist and here the 
usual practice is to estimate them from theoretical or empirical models that have been developed on the basis of measured values. [6]. Therefore, a number of correlations and method shave been developed to estimate daily or monthly global solar radiation on the basis of the more readily available meteorological data ata majority of weather stations. Empirical models which have been used to calculate solar radiation are usually based on the following factors [4, 7, 8]: (1) Astronomical factors (solar constant, earth-sun distance, solar declination and hour angle). (2) Geographical factors (latitude, longitude and elevation of the site). (3) Geometrical factors (azimuth angle of the surface, tilt angle of the surface, sun elevation angle, sun azimuth angle). (4) Physical factors (scatteringo fair molecules, water vapor content, scattering of dust and other atmospheric constituentssuchas $\mathrm{O}_{2}, \mathrm{~N}_{2}, \mathrm{CO}_{2}, \mathrm{O}$, etc.). (5) Meteorological factors (extraterrestrial solar radiation, sunshine duration, temperature, precipitation, relative humidity, effects of cloudiness, soil temperature, evaporation, reflection of the locality, etc.).

The objective of this study is to validate, develop and analyze different types of correlation models that used to estimate monthly average daily global solar radiation on a horizontal surface from meteorological parameters: Sunshine hours and measured Temperature and to recommend the most appropriate models for Tepi, using measured data of sunshine hours and temperature in Tepi, Ethiopia.

\subsection{Extraterrestrial Solar Radiation}

The daily average extraterrestrial radiation on a horizontal surface $\left(\mathrm{H}_{\mathrm{o}}\right)$ can be computed from the following equation [4, 8, 23]:

$$
H_{o}=\frac{24 \times 3600 I_{s c}}{\pi}\left(1+0.033 \cos \left(\frac{360 n}{365}\right)\right) x\left(\cos \varphi \cos \delta \sin \omega_{s}+\frac{\pi \omega_{s}}{180} \sin \varphi \sin \delta\right)
$$

Where $\mathrm{H}_{\mathrm{o}}$ daily average extraterrestrial radiation $\left(\mathrm{MJ} / \mathrm{m}^{2}\right.$ day), $\mathrm{I}_{\mathrm{sc}}$ is the solar constant $\left(1367 \mathrm{~W} / \mathrm{m}^{2}\right), \varphi$ the latitude of the site, $\delta$ the solar declination, $\omega_{s}$ the mean sunrise hour angle for the given month and $n$ the number of days of the year starting from first January. The solar declination in degree $(\delta)$ and the mean sunrise hour angle $\left(\omega_{s}\right)$ can be calculated by using, the following equation $[8,9,10]$ :

$$
\delta=23.45 \sin \left(360 \frac{(284+n)}{365}\right)
$$

or from the more accurate equation (error $\left.<0.035^{\circ}\right)$ [9]

$$
\delta=\left(\frac{180}{\pi}\right)(0.006918-0.399912 \cos \gamma+0.070257 \sin \gamma-0.006758 \cos 2 \gamma+0.000907 \sin 2 \gamma-0.002697 \cos 3 \gamma+0.00148 \sin 3 \gamma)
$$

Where $\gamma$ is the day angle (in radian)and given by

$$
\begin{gathered}
\gamma=\frac{2 \pi(n-1)}{365} \\
\omega_{s}=\cos ^{-1}(-\tan \varphi \tan \delta)
\end{gathered}
$$

For a given month, the maximum possible sunshine duration (monthly average day length, $\mathrm{S}_{\mathrm{o}}$ ) can be computed by using $[4,8,23]$ :

$$
S_{o}=\frac{2 \omega_{s}}{15}
$$

\subsection{Correlation Models}

Several empirical methods have been proposed to estimate daily radiation from commonly observed meteorological parameters such as sunshine hours, temperature, cloud cover etc.

If sunshine duration data are available, the classical form of Angström-Prescott $[8,11]$ can be used successfully to estimate daily radiation. When the locations of interest do not have sunshine duration records; air daily temperature, a common worldwide measured parameter, can be used to estimate atmospheric transmittance and subsequently compute daily radiation values.

\subsubsection{Sunshine Based Models}

The most commonly used parameter for estimating global solar radiation is sunshine duration.
Angstrom-Prescott model [11]

$$
\frac{H}{H_{o}}=a+b\left(\frac{s}{s_{o}}\right)
$$

where $\mathrm{H}$ is the monthly average daily global radiation, $\mathrm{H}_{\mathrm{o}}$ is the monthly average daily extraterrestrial radiation, $\mathrm{S}$ is the monthly average daily hours of bright sunshine (h), $\mathrm{S}_{\mathrm{o}}$ is the monthly average day length $(\mathrm{h})$, and $\mathrm{a}$ and $\mathrm{b}$ are empirical coefficients.

Ogelman et al., model

Ogelman et al., have correlated $\left(\mathrm{H} / \mathrm{H}_{\mathrm{o}}\right)$ with $\left(\mathrm{S} / \mathrm{S}_{\mathrm{o}}\right)$ in the form of a second order polynomial equation [12]:

$$
\frac{H}{H_{o}}=a+b\left(\frac{s}{s_{o}}\right)+c\left(\frac{s}{s_{o}}\right)^{2}
$$

Where $a, b$ and $c$ are empirical coefficients.

Samuel model

Samuel has correlated $\mathrm{H} / \mathrm{H}_{0}$ with $\mathrm{S} / \mathrm{S}_{0}$ in the for mofathird order polynomial equation [13]:

$$
\frac{H}{H_{o}}=a+b\left(\frac{s}{s_{o}}\right)+c\left(\frac{s}{s_{o}}\right)^{2}+d\left(\frac{s}{s_{o}}\right)^{3}
$$

Where $a, b, c$ and $d$ are empirical coefficients.

Newland model

A linear-logarithmic model has been used by New land to obtain the best correlation between $\mathrm{H} / \mathrm{H}_{0}$ and $\mathrm{S} / \mathrm{S}_{0}$ [14]: 


$$
\frac{H}{H_{o}}=a+b\left(\frac{s}{s_{o}}\right)+\operatorname{cog}\left(\frac{s}{s_{o}}\right)
$$

Where $\mathrm{a}, \mathrm{b}$ and $\mathrm{c}$ are empirical coefficients to be determined.

Bakirci model

Bakirci developed linear exponential and power models which is a derivation of the modified Angstrom-type equation [15]:

$$
\begin{gathered}
\frac{H}{H_{o}}=a+b\left(\frac{s}{s_{o}}\right)+c \exp \left(\frac{s}{s_{o}}\right) \\
\frac{H}{H_{o}}=a\left(\frac{s}{s_{o}}\right)^{b}
\end{gathered}
$$

Elagib and Mansell Model

Elagib and Mansell proposed the following equation for predicting solar radiation based on sunshine hours [16]:

$$
\frac{H}{H_{o}}=a \exp \left(b \frac{s}{s_{o}}\right)
$$

where the empirical coefficients $a$ and $b$ to be determined for the given location

\subsubsection{Temperature Based Models}

Due to the common availability of daily maximum and minimum air temperatures, several empirical methods have been proposed to estimate solar radiation from these variables, especially for locations where the air daily temperature is the only available meteorological data.

Hargreaves model

Hargreaves and Samani recommended simple equation to estimate solar radiation using only maximum and minimum temperatures [17]:

$$
\frac{H}{H_{o}}=a\left(T_{\max }-T_{\min }\right)^{0.5}
$$

Annandale et al., model

Annandale et al., proposed the following correlation [22]:

$$
\begin{gathered}
\frac{H}{H_{o}}=a\left(1+2.7 \times 10^{-5} Z\right)\left(T_{\text {max }}-T_{\text {min }}\right)^{0.5} \quad(15) \quad \frac{H}{H_{o}}=a+b\left(T_{\text {max }}-T_{\text {min }}\right)^{0.5}+c\left(T_{\text {max }}-T_{\text {min }}\right) \\
\frac{H}{H_{o}}=a+b\left(T_{\text {max }}-T_{\text {min }}\right)^{0.5}+c\left(T_{\text {max }}-T_{\text {min }}\right)+d\left(T_{\text {max }}-T_{\text {min }}\right)^{1.5} \\
\frac{H}{H_{o}}=a+b \ln \left(T_{\text {max }}-T_{\text {min }}\right)+c\left(\ln \left(T_{\text {max }}-T_{\text {min }}\right)\right)^{2}+d\left(\ln \left(T_{\text {max }}-T_{\text {min }}\right)\right)^{3}
\end{gathered}
$$

\section{Methodology}

\subsection{Site Description and Meteorological Parameters}

The data on sunshine hours, minimum and maximum temperatures used in this study were obtained from Ethiopian Institute of Agricultural Research: Tepi National Spices Research Center. The site considered in this study is Tepi and
Where $Z$ is the elevation above sea level in meter.

Bristow and Campbell Model

Bristow and Campbell $[10,24]$ suggested the following relationship for daily $\mathrm{H}$, as a function of daily $\mathrm{H}_{\mathrm{o}}$ and the difference between maximum and minimum temperatures $\left(\Delta T,{ }^{\circ} \mathrm{C}\right)$ :

$$
\frac{H}{H_{o}}=a\left(1-\exp \left(-b \Delta T^{c}\right)\right)
$$

Although coefficients a, b and c are empirical, they have some physical meaning. Coefficient are presents the maximum radiation that can be expected on a clear day. Coefficients $b$ and $c$ control the rate at which $a$ is approached as the temperature difference increases. Values most frequently reported for these coefficients are 0.7 for $a$, ranges from 0.004 to 0.010 for $b$ and 2.4 for $c[18,24]$.

Meza and Varas model

Meza and Varas assumed that $a$ and $c$ coefficients of Bristow-Campbell model are fixed and the only b coefficient was adjusted to minimize the square errors [18]:

$$
\frac{H}{H_{o}}=0.75\left(1-\exp \left(-b \Delta T^{2}\right)\right)
$$

Chen et al. model

Chen et al. developed the following models [19]:

$$
\begin{aligned}
& \frac{H}{H_{o}}=a\left(T_{\text {max }}-T_{\text {min }}\right)^{0.5}+b \\
& \frac{H}{H_{o}}=a \ln \left(T_{\text {max }}-T_{\text {min }}\right)+b
\end{aligned}
$$

Where $a$ and $b$ are empirical coefficients.

Proposed models

Due to the widely and common availability of daily maximum and minimum air temperatures data in wide meteorological station; developing some precise solar radiation models which use commonly available measured parameters such as air temperature is crucial.

it is located in south west of Ethiopia, on latitude of $7.20^{\circ} \mathrm{N}$, longitude of $35.42^{\circ} \mathrm{E}$ and altitude of $1097 \mathrm{~m}$ above sea level. The sunshine hours are recorded by Campbell-Stokes sunshine recorder. The respective data collected for the location were the monthly averages sunshine hours for 4 year (2013-2016) and monthly averages maximum and minimum Temperature for 5 year (2012-2016). The monthly average daily global solar radiation on horizontal surfaces was obtained from the archives of National Aeronautics and Space Administration (NASA), a 22 year period 1983-2005 [20].

These data were analyzed and processed using spreadsheet 
and MATLAB computer software.

\subsection{Statistical Evaluation of Models}

The calculated values of global solar radiation generated from the correlation models were compared with the measured values for the location under study. The performance of the above models was evaluated using the methods of statistical analysis $[1,6,21,23]$ : the coefficient of determination $\mathrm{R}$-squared $\left(\mathrm{R}^{2}\right)$, root mean square error (RMSE), mean bias error (MBE), mean percentage error (MPE), mean absolute percentage error (MAPE) mean absolute bias error (MABE) and correlation coefficient (r). These error indices are defined as:

$$
\begin{gathered}
R^{2}=1-\frac{\sum_{i=1}^{n}\left(H_{i, m}-H_{i, c}\right)^{2}}{\sum_{i=1}^{n}\left(H_{i, m}-\bar{H}_{m}\right)^{2}} \\
R M S E=\left[\frac{1}{n} \sum_{i=1}^{n}\left(H_{i, m}-H_{i, c}\right)^{2}\right]^{\frac{1}{2}} \\
M B E=\frac{1}{n} \sum_{i=1}^{n}\left(H_{i, m}-H_{i, c}\right) \\
M A B E=\frac{1}{n} \sum_{i=1}^{n}\left|\left(H_{i, m}-H_{i, c}\right)\right| \\
M P E(\%)=\frac{1}{n} \sum_{i=1}^{n}\left(\frac{\left(H_{i, m}-H_{i, c}\right)}{H_{i, m}}\right) x 100 \\
M A P E(\%)=\frac{1}{n} \sum_{i=1}^{n}\left|\left(\frac{\left(H_{i, m}-H_{i, c}\right)}{H_{i, m}}\right)\right| x 100 \\
r=\frac{\sum_{i=1}^{n}\left(H_{i, c}-\bar{H}_{c}\right)\left(H_{i, m}-\bar{H}_{m}\right)}{\left[\sum_{i=1}^{n}\left(H_{i, m}-\bar{H}_{m}\right)^{2} \sum_{i=1}^{n}\left(H_{i, c}-\bar{H}_{c}\right)^{2}\right]^{\frac{1}{2}}}
\end{gathered}
$$

Where, the subscripts " $c$ " and " $\mathrm{m}$ " refer to the calculated and measured global solar irradiation values, respectively. $\bar{H}_{c}$ is the mean calculated global radiation and $\bar{H}_{m}$ is the mean measured global radiation. The low values of RMSE, MBE, MPE, MABE and MAPE are desirable but correlation coefficient (r) should approach to1 as closely as possible. Coefficient of determination $\left(\mathrm{R}^{2}\right)$ is a statistical measure of how well the regression line approximates the real data points. RMSE provides information on the short-term performance of the correlations by allowing a term by term comparison of the actual deviation between the estimated and measured values. It is also possible to have large RMSE values at the same time a small MBE or vice versa. The positive MBE and MPE shows overestimation while the negative MBE and MPE indicates under-estimation of the values [6, 23]. Error measures with absolute values (such as MABE and MAPE) provide valuable information because they do not have the problem of errors of opposite signs cancelling themselves out; a low mean error can at times be misleading but this is avoided with absolute error measures which provide the average total magnitude of the error. On the other hand, absolute error measures can also assume a symmetric loss function through the total magnitude of error without the true bias or direction of the error. Hence, when using the mean absolute values, it is also useful to compute a measure of bias $[1,6,23]$.

\section{Results and Discussion}

\subsection{Monthly Average Daily Solar Radiation and Clearness Index}

Estimation of solar radiation from the measured meteorological variables offers an important alternative in the absence of measured solar radiation. The monthly averaged daily solar radiation $\left(\mathrm{H}_{\mathrm{m}}\right)$, fraction of sunshine hour $\left(\frac{s}{s_{0}}\right)$, clearness index $\left(\frac{H_{m}}{H_{0}}\right)$, maximum and minimum temperature for Tepi is presented in Table 1.

The classifications on sunshine recorders vary, depending on site and season, according to the dominant cloud formation. The latter can be roughly described by three ranges of relative daily sunshine hour $\left(\frac{s}{s_{0}}\right)$, namely (1) Cloudy sky by $\left(0 \leq \frac{s}{s_{0}}<\right.$ $0.3)$, (2) Scattered clouds by $\left(0.3 \leq \frac{s}{s_{0}}<0.7\right)$ and (3) Fair weather by $\left(0.7 \leq \frac{s}{s_{0}} \leq 1.0\right)$ [25]. According to this classification the prevailing sunshine condition in Tepi is mainly scattered clouds sky except during July to September when it can be considered as cloudy sky condition.

The clearness index provides information on the level of availability of solar radiation at the surface of the earth as well as changes in atmospheric conditions [26-28]. The clearness index of Tepi ranges from $0.45-0.60$, which indicates the prevailing weather condition is partly overcast weather.

Table 1. Monthly average daily solar radiation, clearness index, fraction of sunshine hours maximum and minimum temperature for Tepi.

\begin{tabular}{lllllllll}
\hline Month & $\begin{array}{l}\mathbf{S} \\
\text { (h) }\end{array}$ & $\begin{array}{l}\mathbf{S}_{\mathbf{o}} \\
(\mathbf{h})\end{array}$ & $\frac{\boldsymbol{S}}{\boldsymbol{S}_{\boldsymbol{o}}}$ & $\mathbf{T}_{\mathbf{m a x}}$ & $\mathbf{T}_{\min }$ & $\mathbf{H}_{\mathrm{m}}$ & $\mathbf{H}_{\mathbf{o}}$ & $\frac{\boldsymbol{H}_{\boldsymbol{m}}}{\boldsymbol{H}_{\boldsymbol{o}}}$ \\
\hline Jan & 5.94 & 11.7 & 0.5077 & 29.5 & 20.6 & 5.52 & 9.23 & 0.5980 \\
Feb & 6.13 & 11.9 & 0.5151 & 30.4 & 21.7 & 5.89 & 9.86 & 0.5974 \\
Mar & 5.62 & 12.0 & 0.4683 & 30.1 & 22.4 & 5.76 & 10.3 & 0.5592 \\
Apr & 5.84 & 12.2 & 0.4787 & 27.4 & 20.9 & 5.48 & 10.4 & 0.5269 \\
May & 5.53 & 12.4 & 0.4460 & 25.1 & 19.1 & 5.04 & 10.2 & 0.4941 \\
Jun & 4.97 & 12.5 & 0.3976 & 25.0 & 18.9 & 4.68 & 10.0 & 0.4680 \\
Jul & 3.47 & 12.5 & 0.2776 & 23.5 & 17.6 & 4.50 & 10.1 & 0.4455 \\
Aug & 2.57 & 12.3 & 0.2089 & 23.9 & 17.5 & 4.72 & 10.3 & 0.4583 \\
Sep & 3.37 & 12.1 & 0.2785 & 24.6 & 18.0 & 5.09 & 10.3 & 0.4942 \\
Oct & 5.21 & 11.9 & 0.4378 & 25.9 & 18.9 & 5.13 & 9.94 & 0.5161 \\
Nov & 6.75 & 11.8 & 0.5720 & 26.8 & 18.6 & 5.20 & 9.35 & 0.5561 \\
Dec & 6.72 & 11.7 & 0.5744 & 27.9 & 19.2 & 5.34 & 8.99 & 0.5940 \\
\hline
\end{tabular}

\subsection{Comparison of Correlation Models: Sunshine-Based} Models and Model Parameters

Many sunshine based models have been employed for estimating global solar radiation in literature. Those models (linear, quadratic, polynomial, logarithmic and exponential functions) which widely used to estimate the monthly average daily global solar radiation are presented in Table 2, with their corresponding model parameters which calibrated based on the measured data for the site. 
Table 2. Models calibration parameters for Tepi: Sunshine-based model.

\begin{tabular}{lllll}
\hline \multirow{2}{*}{ Models } & \multicolumn{4}{l}{ Model parameters } \\
\cline { 2 - 5 } & $\boldsymbol{a}$ & $\boldsymbol{b}$ & $\boldsymbol{c}$ & $\boldsymbol{d}$ \\
\hline Angstrom-Prescott model & 0.3580 & 0.3896 & & \\
Ogelman et al., model & 0.4659 & -0.2104 & 0.7587 & \\
Samuel model & 0.9290 & -4.0750 & 10.7669 & -8.1991 \\
Newland model & -0.1481 & 1.0549 & -0.5713 & \\
Bakirci model (eq.11) & -0.4318 & -0.9106 & 0.8719 & \\
Bakirci model (eq.12) & 0.6628 & 0.2676 & & \\
Elagib and Mansell model & 0.3784 & 0.7516 & & \\
\hline
\end{tabular}

Moreover, to evaluate the accuracy and applicability of collected models for estimating the monthly average daily global radiation on a horizontal surface, the long term measured meteorological data of sunshine hours of Tepi is employed. The models were then compared with each other on the basis of the statistical error indicators such as R2, RMSE, MBE, MABE and MAPE. The most accurate models are identified and presented in Figure 1. These models have reasonable values of estimation errors. Based on the statistical results, Table 3, Samuel and Newland sunshinebased model reproduce the measured monthly average daily global solar radiation for Tepi with the high accuracy. For the location considered, Tepi, these models (Samuel and Newland models) with their corresponding empirical coefficients are given as follows, respectively:

$$
\begin{gathered}
\frac{H}{H_{o}}=0.9290-4.0750\left(\frac{s}{s_{o}}\right)+10.7669\left(\frac{s}{s_{o}}\right)^{2}-8.1991\left(\frac{s}{s_{o}}\right)^{3} \\
\frac{H}{H_{o}}=-0.1481+1.0549\left(\frac{s}{s_{o}}\right)-0.5713 \log \left(\frac{s}{s_{o}}\right)
\end{gathered}
$$

Therefore, it can be recommended that these models are used reasonably well for estimating the solar radiation at Tepi and possibly in its surroundings sites with similar climatic conditions.

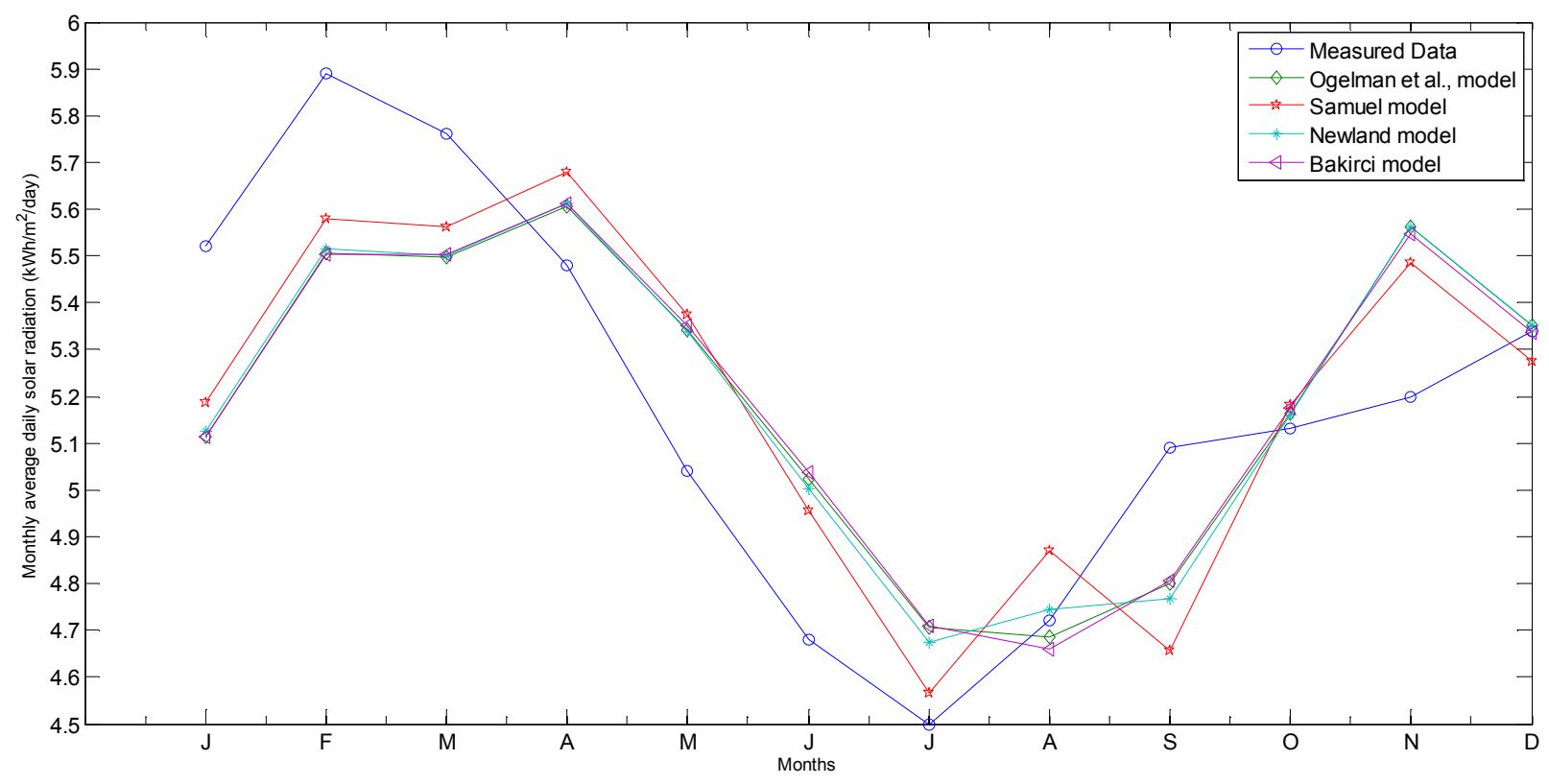

Figure 1. The comparison between observed and estimated values of monthly average daily solar radiation $\left(\mathrm{kWh} / \mathrm{m}^{2} /\right.$ day) for Tepi, Sunshine-based models.

Table 3. $R^{2}, R M S E, M B E, M A B E, M P E$ and MAPE computed in the comparison between measured and estimated monthly average daily solar radiation.

\begin{tabular}{lllllll}
\hline Models & \multicolumn{2}{l}{ Statistical analysis methods } & & & \\
\hline & $\boldsymbol{R}^{\mathbf{2}}$ & RMSE & MBE & MABE & MPE & MAPE \\
\hline Angstrom-Prescott model & 0.5187 & 0.2849 & -0.0029 & 0.2629 & -0.2974 & 5.0929 \\
Ogelman et al., model & 0.5728 & 0.2684 & -0.0010 & 0.2299 & -0.2722 & 4.4032 \\
Samuel model & 0.6154 & 0.2546 & -0.0017 & 0.2253 & -0.2327 & 4.3160 \\
Newland model & 0.5839 & 0.2649 & $-6.5 \times 10^{-4}$ & 0.2258 & -0.2579 & 4.3149 \\
Bakirci model (eq.11) & 0.5682 & 0.2698 & $-6.32 \times 10^{-4}$ & 0.2333 & -0.2649 & 4.4781 \\
Bakirci model (eq.12) & 0.4579 & 0.3023 & 0.0054 & 0.2781 & -0.1672 & 5.3994 \\
Elagib and Mansell model & 0.5360 & 0.2797 & 0.0060 & 0.2558 & -0.1343 & 4.9389 \\
\hline
\end{tabular}

\subsection{Comparison of Correlation Models: Temperature- Based Models and Model Parameters}

Estimation of global solar radiation from the air temperature offers an important alternative in the absence of measured solar radiation, sunshine hours or other meteorological parameters because of the wide availability of air temperature data. Temperature based models are a convenient tool for estimating solar radiation if the parameters can be calibrated for each specific location [10]. The empirical coefficients, model parameters, derived for existing and developed models for this site are presented in Table 4. 
Table 4. Models calibration parameters for Tepi: Temperature-based model.

\begin{tabular}{lllll}
\hline Models & \multicolumn{4}{l}{ Model parameters } \\
\hline & $\boldsymbol{a}$ & $\boldsymbol{b}$ & $\boldsymbol{c}$ & $\boldsymbol{d}$ \\
Hargreaves model & 0.1958 & - & - & - \\
Annandale et al., model & 0.1908 & - & - & - \\
Bristow and Campbell model & 0.70 & 0.0120 & 2.4 & - \\
Meza and Varas model & 0.75 & 0.0240 & 2 & - \\
Chen et al., model (eq.18) & -0.1350 & 0.2468 & - & - \\
Chen et al., model (eq.19) & 0.3334 & -0.1298 & - & - \\
Proposed models & & & & \\
Equation (20) & -0.4271 & 0.4631 & -0.0399 & - \\
Equation (21) & -8.0530 & 8.9882 & -3.2083 & 0.3915 \\
Equation (22) & -6.9938 & 10.8299 & -5.3361 & 0.9017 \\
Equation (23) & -0.1329 & 0.1220 & 0.1686 & - \\
Equation (24) & 0.0665 & -0.0040 & - & - \\
\hline
\end{tabular}

The comparison between the measured and predicted global solar radiation using models from literature and developed models those with better statistical performance are presented in Figure 2. It is clear from this figure, these models show better agreement between the predicted and measured global solar radiation. In particular, the developed model (Equation 24) has a more accurate overall prediction.

The performance of each model is evaluated and compared using statistical error parameters $\mathrm{R}^{2}$, RMSE, MBE, MABE, MPE and MAPE. The summary of the error analysis is presented in Table 5 .

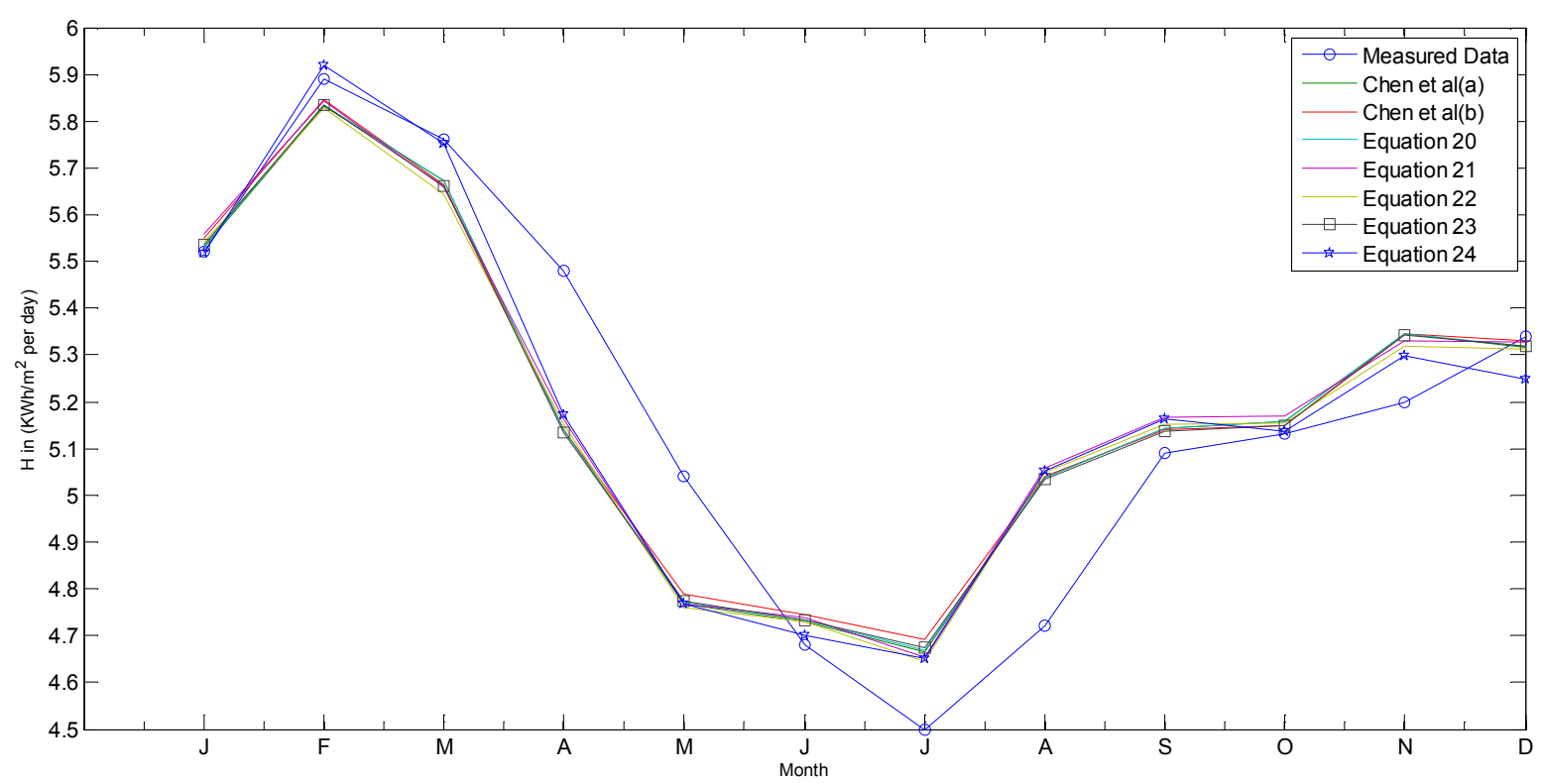

Figure 2. The comparison between observed and estimated values of monthly average daily solar radiation (kWh/m2/day) for Tepi, Temperature-based models.

For the location considered, Tepi, according model performance evaluation Chen et al. models (eq. 18 and 19) can be used and with their corresponding empirical coefficients are given as follows, respectively:

$$
\begin{gathered}
\frac{H}{H_{o}}=-0.1350\left(T_{\max }-T_{\min }\right)^{0.5}+0.2468 \\
\frac{H}{H_{o}}=0.3334 \ln \left(T_{\max }-T_{\min }\right)-0.1298
\end{gathered}
$$

It can further be observed from Table 5 and Figure 2 that the estimation of global solar radiation can be predicted with reasonable accuracy with all developed models considered in this study. Equation (24) is the best overall, due to its simplicity and better model performance evaluation and apart from empirical coefficients there are some models in literature which has similar form with this model $[29,30]$. Therefore, it can be recommended that this mode lis used reasonably well for estimating the solar radiation in Tepi and possibly in its surroundings sites with similar climatic conditions if empirical coefficients $a$ and $b$ are correctly adjusted; with its corresponding empirical coefficients (eq. 24) for Tepi:

$$
H=0.0665\left(T_{\max }-T_{\min }\right)^{0.7} H_{0}^{1.3}-0.0040
$$

\begin{tabular}{|c|c|c|c|c|c|c|}
\hline \multirow{2}{*}{ Models } & \multicolumn{6}{|c|}{ Statistical analysis methods } \\
\hline & $R^{2}$ & RMSE & MBE & MABE & MPE & MAPE \\
\hline Hargreaves model & 0.7621 & 0.2003 & -0.0108 & 0.1722 & -0.1407 & 3.3845 \\
\hline Annandale et al., model & 0.7628 & 0.2000 & -0.0108 & 0.1718 & -0.4738 & 3.3957 \\
\hline Bristow and Campbell model & 0.5303 & 0.2814 & 0.0951 & 0.2519 & 2.1069 & 4.9293 \\
\hline Meza and Varas model & 0.3728 & 0.3252 & 0.0024 & 0.2751 & 0.2368 & 5.2790 \\
\hline Chen et al., model (eq.18) & 0.8229 & 0.1728 & -0.0068 & 0.1301 & -0.2794 & 2.5748 \\
\hline Chen et al., model (eq.19) & 0.8240 & 0.1723 & $6.81 \times 10^{-4}$ & 0.1291 & -0.1303 & 2.5478 \\
\hline Equation (20) & 0.8239 & 0.1723 & $-6.22 \times 10^{-4}$ & 0.1292 & -0.1560 & 2.5505 \\
\hline
\end{tabular}

Table 5. Models performance evaluation: Temperature-based model. 


\begin{tabular}{|c|c|c|c|c|c|c|}
\hline \multirow{2}{*}{ Models } & \multicolumn{6}{|c|}{ Statistical analysis methods } \\
\hline & $R^{2}$ & RMSE & MBE & MABE & MPE & MAPE \\
\hline Equation (21) & 0.8246 & 0.1720 & -0.0074 & 0.1323 & -0.2835 & 2.6113 \\
\hline Equation (22) & 0.8245 & 0.1720 & 0.0051 & 0.1305 & -0.0436 & 2.5653 \\
\hline Equation (23) & 0.8237 & 0.1724 & 0.0021 & 0.1288 & -0.1055 & 2.5400 \\
\hline Equation (24) & 0.8383 & 0.1651 & -0.0026 & 0.1161 & -0.1595 & 2.3099 \\
\hline
\end{tabular}

\section{Conclusions}

Estimation of solar radiation from measured meteorological variables offers an important alternative in absence of measured solar radiation. The existing and developed models are comparatively studied and evaluated using monthly average daily solar radiation and measured meteorological data, monthly average daily sunshine duration, maximum and minimum temperatures. The performance of each model is evaluated and compared using statistical error parameters $\mathrm{R}^{2}$, RMSE, MBE, MABE, MPE and MAPE.

The most important outcomes of the study can be summarized as follows:

1. According to classification of $\mathrm{s} / \mathrm{s}_{0}$, which ranges from $0.21-0.60$, the prevailing sunshine condition in Tepi is mainly scattered clouds sky except during July to September when it can be considered as cloudy sky condition. Moreover, the clearness index of Tepi ranges from $0.45-0.60$, which indicates the prevailing weather condition is partly overcast weather.

2. Several sunshine based models have been employed for estimating global solar radiation in literature. For Tepi, Samuel and Newland models show a better overall, $\mathrm{R}^{2}$, RMSE, MBE, MABE, MPE and MAPE.

3. Temperature based empirical models to estimate monthly average daily solar radiation is a convenient tool if the parameters can correctly be calibrated for different locations. These models have the advantage of using meteorological data which are commonly and widely available. From literature, Chen et al. models can adequately be used for this site.

4. The estimation of global solar radiation can be predicted with reasonable accuracy with all developed models considered in this study. In particular, equation (24) is the best overall, due to its simplicity and better model performance evaluation.

5. Therefore, it can be recommended that these models are used reasonably well for estimating the solar radiation in Tepi and possibly in its surroundings sites with similar climatic conditions if empirical coefficients are correctly calibrated.

6. The models that have been chosen and developed are those for which the data are commonly and widely available. The models are appropriate to estimate solar radiation for agricultural and incoming solar radiation potential for the site. However, further study is recommended for thorough treatment of atmospheric transmittance, solar radiation spectral response and absorption of photovoltaic device for better solar energy utilization.

\section{References}

[1] Badescu V., 2008. Modeling Solar Radiation at the Earth's Surface: Recent Advances; Berlin Heidelberg, Springer-Verlag.

[2] Asress M. B., Aleksandar S, Dragan K., Slobodan S., 2013. Wind energy resource development in Ethiopia as an alternative energy future beyond the dominant hydropower. Renewable and Sustainable Energy Reviews 23: 366-378.

[3] Ministry of Water \& Energy (MoWE), 2011. Energy Sector Mapping \& Database Development. First phase report.

[4] Norton B., 2014. Harnessing Solar Heat; Springer, Dordrecht Heidelberg.

[5] Lunde P. J., 1980. Solar thermal engineering. Wiley, New York.

[6] Sen Z., 2008. Solar energy fundamentals and modeling techniques: atmosphere, environment, climate change and renewable energy; London, Springer-Verlag.

[7] Ertekin C., Yaldiz O., 1999. Estimation of monthly average daily global radiation on horizontal surface for Antalya, Turkey. Renewable Energy; 17: 95-102.

[8] Duffie J. A., Beckman W. A., 2013. Solar engineering of thermal processes. $4^{\text {th }}$ ed, New York: Wiley.

[9] Spencer J. W., 1971. Fourier series representation of the position of the Sun. Search; 2: 172.

[10] Almorox J., Hontoria C., Benito M., 2011. Models for obtaining daily global solar radiation with measured air temperature data in Madrid (Spain). Applied Energy; 88: 1703-9.

[11] Prescott J. A., 1940. Evaporation from water surface in relation to solar radiation. Transactions of the Royal Society of Australia; 46: 114-8.

[12] Ogelman H., Ecevit A., Tasdemiroglu E., 1984. A new method for estimating solar radiation from bright sunshine data. Solar Energy; 33: 619-25.

[13] Samuel TDMA., 1991. Estimation of global radiation for Sri Lanka. Solar Energy; 47: 333-7.

[14] Newland F. J., 1988. A study of solar radiation models for the coastal region of South China. Solar Energy; 31: 227-35.

[15] Bakirci K., 2009. Correlations for estimation of daily global solar radiation with hours of bright sunshine in Turkey. Energy 2009; 34: 485-501.

[16] Elagib N., Mansell M., 2000. New approaches for estimating global solar radiation across Sudan. Energy Conversion and Management; 41: 419-34. 
[17] Hargreaves G. H., Samani Z. A., 1982. Estimating potential evapo-transpiration. Journal of Irrigation and Drainage Engineering; 108 (IR3): 223-30.

[18] Meza F., Varas E., 2000. Estimation of mean monthly solar global radiation as a function of temperature. Agricultural and Forest Meteorology; 100: 231-241.

[19] Chen R., Ersi K., Yang J., Lu S., Zhao W., 2004. Validation of five global radiation models with measured daily data in China. Energy Conversion and Management; 45: 1759-69.

[20] http://eosweb.larc.nasa.gov/sse/.

[21] Yorukoglu M., Celik A., 2006. A critical review on the estimation of daily global solar radiation from sunshine duration. Energy Conversion and Management; 47: 2441-50.

[22] Annandale J. G., Jovanic N. Z., Benade N., Allen R. G., 2002. Software for missing data error analysis of Penman-Monteith reference evapo-transpiration. Irrigation Science; 21: 57-67.

[23] Muneer T., 2004. Solar Radiation and Daylight Models, $2^{\text {nd }}$ ed., Elsevier Butterworth-Heinemann.

[24] Bristow K. L., Campbell G. S., 1984. On the relationship between incoming solar radiation and daily maximum and minimum temperature. Agric Forest Meteorology; 31: 59166.

[25] World Meteorological Organization; 2008. Guide to meteorological instruments and methods of observation. $7^{\text {th }}$ ed. Geneva.

[26] Adaramola M. S., 2012. Estimating global solar radiation using common meteorological data in Akure, Nigeria; Renewable Energy 47: 38-44.

[27] Jiang Y., 2009. Correlation for diffuse radiation from global solar radiation and sunshine data at Beijing China. Journal of Energy Engineering; 135: 107-111.

[28] Iqbal M., 1980. Prediction of hourly diffuse solar radiation from measured hourly global radiation on a horizontal surface. Solar Energy; 24: 491-503.

[29] Mahmood R., Hubbar K. G., 2002. Effect of time of temperature observation and estimation of daily solar radiation for the Northern Great Plains, USA. Agronomy Journal; 94: 723-33.

[30] Hunt L. A., Kucharb L., Swanton C. J., 1998. Estimation of solar radiation for use in crop modeling. Agricultural and Forest Meteorology; 91: 293-300. 